\title{
Análise de jogos digitais em dispositivos móveis para aprendizagem de línguas estrangeiras
}

\section{Analysis of digital games for foreign/second language learning in mobile devices}

Josiane Brunetti Cani*

Universidade Federal de Minas Gerais

Belo Horizonte, Minas Gerais/ Brasil

Ivana Queiroz Pinheiro**

Universidade Federal de Minas Gerais

Belo Horizonte, Minas Gerais/ Brasil

Maria Elizabete Villela Santiago ${ }^{* * *}$

Universidade Federal de Minas Gerais

Belo Horizonte, Minas Gerais/ Brasil

Gilvan Mateus Soares ${ }^{* * * *}$

Universidade Federal de Minas Gerais

Belo Horizonte, Minas Gerais/ Brasil

\begin{abstract}
RESUMO: A pesquisa objetiva analisar três aplicativos de dispositivos móveis orientados à aprendizagem de língua estrangeira, identificando suas potencialidades e limitações: Lingualeo, English Grammar All Levels e Learning 2 Talk. Para alcançar tal objetivo, a pesquisa teve como fundamentação teórica os estudos sobre gamificação e aprendizagem de línguas pelo computador (CALL) a fim de analisar os dados obtidos nos três jogos de acordo com os seguintes critérios: i) teoria de aprendizagem; ii) nível de contextualização; iii) nível de personalização; iv) tipo de interação; v) conteúdo abordado; e vi) interface. Utilizou-se uma abordagem qualitativa, abrangendo aspectos tanto da linguagem verbal quanto gráfica, além dos elementos interativos das interfaces. A análise
\end{abstract}

\footnotetext{
*josicani@gmail.com

**ivanaqpinheiro@gmail.com

*** elizabetesantiago@unifei.edu.br

**** gilvanso@uol.com.br
} 
permitiu concluir que, embora predomine uma estrutura behaviorista, há uma tentativa de expandir o ensino de língua estrangeira por meio de jogos digitais.

PALAVRAS-CHAVE: aprendizagem de línguas por computador (CALL); jogos digitais; mediação pedagógica.

\begin{abstract}
This research aims to analyze three mobile device apps for foreign language learning, identifying their potentialities and limitations: Lingualeo, English Grammar All Levels and Learning 2 Talk. To achieve this objective, the research was based on theoretical studies on gamification and computer assisted language learning (CALL) in order to analyze the data obtained in the three games according to the following criteria: i) learning theory; ii) level of contextualization; iii) level of customization; iv) type of interaction; v) content addressed; and vi) interface. A qualitative approach was used, covering aspects of both verbal and graphic language, as well as interactive interface elements. The analysis concluded that, although the games present the predominance of a behaviorist structure, they attempt to expand the teaching of the foreign language.
\end{abstract}

KEYWORDS: computer assisted language learning (CALL); digital games; pedagogical mediation.

\title{
1 Introdução
}

A onipresença das tecnologias portáteis marca, nos últimos anos, a potencialização dos meios de comunicação. Com a facilidade da conexão sem fio, as pessoas fazem uso dos mais diversos dispositivos para o desenvolvimento de diferentes tarefas, desde localização de ruas, restaurantes, cinemas e estradas sem congestionamento, até efetivação de compras, operações bancárias, pesquisas sobre o clima e muitas outras comodidades.

Entre essas utilidades, novas formas de interação têm sido assinaladas pela continuidade da expansão das tecnologias e pela oportunidade de atender a interesses tanto individuais quanto coletivos nas relações sociais e profissionais. Tamanha interação não pode ser excluída da escola, na medida em que o letramento digital assume importância social no que se refere ao uso das tecnologias nas práticas de leitura e escrita. Essa constatação surge como uma possibilidade de conectar a educação ao universo dos jovens, o que nos leva a refletir sobre propostas que promovam o ensino por meio de jogos, de forma colaborativa, autônoma e multifacetada. Trabalhando com sujeitos múltiplos, em locais distintos, as tecnologias digitais e a internet podem se configurar como aliadas para tornar o ensino mais dinâmico, possibilitando mudanças na educação. O desenvolvimento de produtos, sistemas, repositórios e portais tem considerado, além dos recursos tecnológicos e fins educacionais, a tendência aos jogos aprimorada pelo 
homem desde épocas remotas. Não desconsiderando os inúmeros exemplos da Grécia antiga, vamos pensar a "recompensa" - como as estrelinhas no caderno do aluno que terminava uma tarefa ou os níveis de um ditado, que podiam variar entre palavras, frases ou textos e evoluíam conforme as habilidades dos usuários (FADEL; ULBRICHT, 2014).

Identificamos, assim, uma realidade de esforço e recompensa como potencialidade não só para o prazer pelo jogo, mas também para o desenvolvimento de habilidades cognitivas que estimulam a memória e a atenção (FURIÓ et al., 2013). Segundo Zichermann e Cunningham (2011), as estratégias utilizadas nos jogos funcionam como estímulo motivador, contribuindo para o engajamento na aprendizagem em um ambiente divertido e lúdico. Esse ambiente, cujo princípio é a apropriação de estratégias que promovam determinado comportamento e motivem o indivíduo, é denominado "gamificação".

A gamificação se consolida como um fenômeno cultural e é pauta de inúmeras investigações na área da computação (ARMELIATO, 2011), da psicologia (FORTIM, 2008) e da comunicação (ZICHERMANN; CUNNINGHAM, 2011) que pressupõem a utilização dos jogos com a finalidade de motivar, envolver e fidelizar clientes de empresas, além de trabalhos que dispensam um olhar especial à educação (DOMÍNGUEZ et al., 2013; KAPP, 2012; LEE; DOH, 2012), vendo na lógica dos games um potencial de ensino. O próprio Ministério da Educação já reconhece os games como objetos de ensino ao credenciar uma plataforma online de aprendizado voltada à preparação para o Exame Nacional do Ensino Médio (Enem) por meio de desafios. A plataforma Geekie Games ${ }^{1}$, desenvolvida pela empresa Geekie, oferece um programa de estudos personalizado para o aluno, baseado em seu interesse por determinado curso superior e na quantidade necessária de horas de estudos diários, apresentando vídeo-aulas, exercícios e resumos, além de simulados.

Conforme Vianna et al. (2013, p. 9), a gamificação tem sido aplicada como opção às abordagens tradicionais, especialmente no que se refere a "encorajar pessoas a adotarem determinados comportamentos, a familiarizarem-se com novas tecnologias, a agilizar seus processos de aprendizado ou de treinamento e a tornar mais agradáveis tarefas consideradas tediosas ou repetitivas".

${ }^{1}$ Disponível em: <http://geekiegames.geekie.com.br/>. Acesso em: 12 maio 2016. 
Compreendemos, então, a importância de estudar estratégias metodológicas estruturadas por intermédio da mecânica de games, com reflexões sobre as possibilidades de uso dessas práticas para realmente envolver os alunos em uma aprendizagem prazerosa.

O desenvolvimento de estudos sobre a utilização de games na educação tem relação tanto com o avanço tecnológico quanto com as teorias de ensino de línguas. Nas últimas quatro décadas, com o advento das novas tecnologias, aumentaram significativamente as funções desempenhadas por computadores, ampliando o campo de ensino de línguas mediado por essas ferramentas, o computer-assisted language learning (CALL). ${ }^{2}$

Com base nesses pressupostos, o objetivo deste trabalho é analisar aplicativos de jogos orientados para a aprendizagem de línguas estrangeiras (LE), identificando suas potencialidades e limitações. Procedemos à análise de três jogos, com foco nos seguintes temas: i) teoria de aprendizagem; ii) nível de contextualização; iii) nível de personalização; iv) tipo de interação; v) conteúdo abordado; e vi) interface. Ademais, organizamos os resultados obtidos em quadros, de acordo com os elementos essenciais de cada jogo.

\section{Evolução histórica de ensino e aprendizagem de CALL}

Warschauer (1996) e Warschauer e Healey (1998) discutem um modelo de CALL cuja história poderia ser identificada pelas fases behaviorista, comunicativa e integrativa. Para os autores, uma fase não implica, necessariamente, rejeitar os programas e métodos da fase anterior, pois as inovações englobam o que já fora apresentado.

A primeira etapa do CALL, desenvolvida na década de 1950 e implementada entre 1960 e 1970, se fundamentava nas teorias behavioristas, cujas atividades de linguagem (estímulo-resposta-recompensa) eram repetitivas (drills), colocando o computador como veículo para entrega de materiais de instrução aos estudantes (WARSCHAUER, 1996). A lógica por trás do modelo behaviorista de ensino, segundo o autor, ainda hoje se reproduz, mas incorporando estratégias mais evoluídas, que incluem: repetição do material de modo a beneficiar a aprendizagem; realização de

\footnotetext{
${ }^{2} \mathrm{O}$ termo computer-assisted language learning, com seu acrônimo, CALL, se justifica neste trabalho pelo uso frequente na literatura internacional, em que, segundo Levy (1997), é o mais consagrado.
} 
exercícios repetitivos pelo computador sem se limitar à apresentação de um único material; e possibilidade que os alunos avancem em seu próprio ritmo.

Ao final de 1970 e início de 1980, o CALL behaviorista se transforma por dois importantes fatores: primeiro, as técnicas behavioristas de ensino e aprendizagem de línguas foram rejeitadas, tanto em nível teórico quanto pedagógico; e, segundo, o surgimento de uma nova fase, com o advento do microcomputador, inaugurou outras possibilidades de ensino.

A segunda etapa do CALL, com abordagem comunicativa, tornouse proeminente nas décadas de 1970 e 1980. Os teóricos dessa abordagem defendiam uma comunicação autêntica, que não teria sido devidamente contemplada nos programas de exercício e nas práticas pedagógicas da fase anterior. Underwood (1984 apud WARSCHAUER, 1996), defensor dessa nova abordagem, advoga que o CALL comunicativo: i) utiliza formulários em vez de formas; ii) desenvolve o ensino implícito da gramática; iii) permite que os alunos gerem expressões originais e os incentiva a isso, ao contrário de uma linguagem pré-fabricada; iv) não se processa por meio de julgamentos, avaliações nem recompensas; v) permite flexibilidade de respostas; vi) procura criar um ambiente natural para uso da língua.

Inúmeros programas foram desenvolvidos nessa fase, dentre eles, cursos de leitura, reescrita de textos e jogos de linguagem (HEALEY; JOHNSON, 1995). Nesses programas, segundo Taylor e Perez (1989), o computador permanece como conhecedor da resposta certa ${ }^{3}$, representando um modelo tutor. No entanto, contrasta com o modelo de exercício e prática, pois envolve o estudante em uma dose significativa de controle e interação. Além disso, acaba por estimular discussões na tentativa de descobrir a resposta certa.

A terceira etapa do CALL, de abordagem integrativa, está baseada em dois importantes avanços tecnológicos da última década: computadores multimídia e internet. A tecnologia multimídia possibilita a integração de uma variedade de mídias (texto escrito e gráfico, som, animação, vídeo), acessada apenas por uma máquina, com todos os recursos interconectados, permitindo que os alunos, por meio do mouse, naveguem por seu próprio caminho (WARSCHAUER, 1996).

Conforme aponta Warschauer (1996), a hipermídia permite uma série de oportunidades para o ensino e a aprendizagem de línguas. Primeiro, porque há uma combinação entre visão e audição, como no mundo real;

3 “Knower-of-the-right-answer" (tradução nossa). 
segundo, pela integração de diferentes habilidades linguísticas, articulando, de forma natural, leitura, escrita, fala e escuta em apenas uma atividade; terceiro, pela possibilidade de que os alunos passem a ter o controle de sua aprendizagem, uma vez que decidem o caminho e o ritmo a ser seguido; por fim, a grande vantagem da hipermídia é facilitar um foco principal, sem desconsiderar um secundário, nas estratégias de aprendizagem.

Embora se reconheça a importância da hipermídia no ensino e na aprendizagem de línguas, alguns problemas vêm à tona no que se refere à qualidade dos programas disponíveis e à formação dos professores para utilizar tais recursos pedagógicos. Nesse sentido, Warschauer (1996) assinala a importância da evolução desses programas para serem capazes de "diagnosticar problemas com pronúncia, sintaxe ou uso e, em seguida, inteligentemente decidir entre uma gama de opções (por exemplo, repetir, parafrasear, retardar, corrigir ou direcionar o aluno para explicações de fundo)". ${ }^{4}$

Com base nessas teorias, procuramos compreender o processo de inserção de jogos no contexto educacional, mais especificamente no ensino de línguas.

\section{Entendendo a gamificação}

Cunhado em 2002 por Pelling (2011), o termo "gamificação" só obteve notoriedade oito anos mais tarde, a partir de McGonigal (2011), autora de Reality is broken: why games make us better and how they can change the world, livro considerado a bíblia da gamificação, que apresentou o seguinte argumento: a soma das horas jogadas pelos frequentadores de World of Warcraft (game online criado em 2001) corresponderia a 5,93 bilhões de anos na resolução de problemas de um mundo virtual. A reflexão sobre esses resultados questiona o que aconteceria se todo esse tempo e esforço fossem investidos para a solução de problemas do mundo real, como aquecimento global, erradicação da pobreza, cura de doenças ou resolução de problemas das grandes cidades (VIANNA et al., 2013).

A gamificação consiste na elaboração de protótipos, sistemas ou modelos com foco nas pessoas, considerando a motivação, o sentimento de enfrentar e vencer desafios e a interatividade. Incide no emprego da

\footnotetext{
4 “To diagnose a student's problems with pronunciation, syntax, or usage and then intelligently decide among a range of options (e.g., repeating, paraphrasing, slowing down, correcting, or directing the student to background explanations)" (tradução nossa).
} 
mecânica de games em situações não inseridas propriamente no contexto dos jogos (MCGONIGAL, 2011; SALEN; ZIMMERMAN, 2012). Algumas empresas utilizam jogos como forma de estimular o desempenho e a capacidade criativa de seus funcionários (YOZO, 1996), assim como programas de televisão têm aumentado significativamente a apresentação de jogos interativos como forma de manter seus telespectadores.

Avançando um pouco mais, destacamos iniciativas nas quais os indivíduos são instigados a resolver problemas sociais. Por esse aspecto, consideramos importante referenciar os estudos de McGonigal (2014) a respeito de "jogos de realidade alternativa: jogos que são projetados para melhorar a vida real ou resolver problemas reais". 5

Destacamos, aqui, os conhecimentos advindos da gamificação no desenvolvimento de aplicativos que se apresentam, de forma significativa, em smartphones e tablets. Esses aplicativos atingem a vários públicos que se utilizam das tecnologias para aprender outras línguas, qualificar serviços, mapear o trânsito, entre outras funções. Assim, se os jogos podem transformar o mundo, conforme afirma McGonigal (2014), é possível que a apropriação de estratégias gamificadas possa auxiliar a motivação dos alunos durante o desenvolvimento de sua aprendizagem. Nesse sentido, torna-se oportuno problematizar a relação entre gamificação e educação, analisando a potencialidade dos jogos no processo de ensino e aprendizagem.

\section{Gamificação e educação: motivação é palavra mágica na aprendizagem}

Como afirma Coscarelli (2009, p. 13), "vivemos o digital, somos o digital, fazemos o digital. Isso faz parte de nós, cidadãos inseridos no mundo contemporâneo, e se não faz, ainda, deveria fazer, ou vai fazer logo". Dessa forma, a escola não pode se distanciar do contexto social que aponta para a necessidade de, em sala de aula, letrar digitalmente o aluno. Protocolos corroborados por séculos legitimam uma gigantesca estrutura que parece relutar em aceitar as transformações ocorridas fora do espaço escolar. Vianna et al. (2013) comparam os atributos do jogo e do trabalho, trazendo uma reflexão sobre envolvimento e motivação de empregados de

\footnotetext{
5 "Alternate reality games: games that are designed to improve real lives or solve real problems" (tradução nossa).
} 
uma empresa. Lançamos mão desses atributos para questionar como seriam aplicáveis no contexto de uma sala de aula:

QUADRO 1 - Comparativo dos atributos no jogo, no trabalho e na sala de aula

\begin{tabular}{|l|l|l|l|}
\hline & No jogo & No trabalho & $\begin{array}{l}\text { Na sala de } \\
\text { aula }\end{array}$ \\
\hline Tarefas & Repetitivas, mas divertidas. & Repetitivas e maçantes. & \\
\hline Feedback & Constante. & Uma vez ao ano. \\
\hline Objetivos & Bem definidos. & Vagos ou contraditórios. \\
\hline Evolução pessoal & Clara e tangível. & Obscura. \\
\hline Regras & Transparentes. & Pouco transparentes. \\
\hline Informações & $\begin{array}{l}\text { Adequadas à necessidade } \\
\text { do momento. }\end{array}$ & $\begin{array}{l}\text { Em demasia e, ainda assim, } \\
\text { insuficientes. }\end{array}$ \\
\hline Status & Bastante visível. & Pouco ou nada visível. \\
\hline Promoção & Meritocracia. & Critérios subjetivos. \\
\hline Colaboração & Presente. & Presente. \\
\hline Risco & Alto. & Baixo. \\
\hline Autonomia & Alta. & De mediana para baixa. \\
\hline Narrativa & Sempre presente. & Raramente presente. \\
\hline Obstáculos & Propositais. & Acidentais. \\
\hline
\end{tabular}

Fonte: Vianna et al. (2013), adaptado pelos autores.

Se os jogos podem apresentar características positivas que se converteriam em estratégias eficazes para o trabalho, será que também poderiam ser utilizados com sucesso pela escola no processo de ensino e aprendizagem? Afinal, a gamificação nas salas de aulas poderia ser uma aliada, com critérios próprios, para a evolução do ensino. Para Fardo (2013, p. 63),

A gamificação pode promover a aprendizagem porque muitos de seus elementos são baseados em técnicas que os designers instrucionais e professores vêm usando há muito tempo. Características como distribuir pontuações para atividades, apresentar feedback e encorajar a colaboração em projetos são as metas de muitos planos pedagógicos. A diferença é que a gamificação provê uma camada mais explícita de interesse e um método para costurar esses elementos de forma a alcançar 
a similaridade com os games, o que resulta em uma linguagem a qual os indivíduos inseridos na cultura digital estão mais acostumados e, como resultado, conseguem alcançar essas metas de forma aparentemente mais eficiente e agradável.

Dessa forma, alguns critérios intrínsecos aos jogos, mediante estratégias bem definidas, podem ser utilizados pela escola de forma dinâmica e envolvente, o que apontaria para uma ressignificação do ensino, de modo que sistemas de pontuação eficientes, como recompensas e estratégias eficazes, com desafios por níveis e criatividade na construção do jogo, estabeleceriam espaços de aprendizagem mais prazerosos, sintonizados com interesses e demandas dos alunos.

No entanto, há pesquisadores que chamam a atenção para a necessidade de analisar criteriosamente as reais contribuições da gamificação na educação. Segundo Deterding et al. (2011), utilizar recompensas como meio de motivação pode não desenvolver o comportamento que a própria recompensa irá premiar. Para Okan (2003), é preciso uma consciência crítica da escola e dos pais para uma compreensão profunda sobre o papel da gamificação em relação à aprendizagem. Resnick (2004), por sua vez, destaca o cuidado com a criação de aplicativos educacionais capazes de levar ao pensamento de que aprender sem diversão poderá configurar a experiência mais desagradável do mundo, fazendo com que muitos percebam o processo de ensino-aprendizagem como maçante, tedioso, necessitando de novas técnicas instrumentais e posturas para se tornar palatável.

Contudo, não se trata de substituir um modelo educacional por outro, como uma aposta na educação que, ao utilizar os meios tecnológicos, estaria isenta de quaisquer problemas de aprendizagem. Trata-se, sobretudo, de inserção com qualidade de tecnologias adequadas às propostas pedagógicas como forma de interação e enredamento em uma era digital, potencializando a construção do conhecimento de forma interativa e colaborativa.

Com base nesses pressupostos, na próxima seção detalhamos os procedimentos metodológicos adotados na nossa pesquisa.

\section{Metodologia}

Este trabalho analisa três jogos digitais utilizados em dispositivos móveis e presentes na web, a saber: Lingualeo, English Grammar All Levels 
e Learning 2 Talk. Esses jogos foram selecionados tendo em vista seu escopo principal: a aprendizagem de LE, no caso, o inglês.

Nossa proposta é apresentar a análise de jogos digitais em dispositivos móveis, numa abordagem qualitativa que abrange aspectos das linguagens verbal e gráfica e dos elementos interativos das interfaces (instrução dos jogos, navegação e processo interativo). Para tanto, organizamos seis categorias:

(i) teoria da aprendizagem - examinamos os tipos de abordagem predominantes nos jogos (behaviorista, comunicativa ou integrativa);

(ii) nível de contextualização - analisamos se as atividades propostas se inserem ou não em contextos de aplicação, como letras de músicas, textos de jornais ou alguma situação de comunicação do dia a dia;

(iii) nível de personalização - verificamos se é permitido ao usuário personalizar o jogo de acordo com as habilidades linguísticas que precisa desenvolver, ou, ainda, se aquele nível se baseia em seus interesses pessoais;

(iv) tipo de interação - refletimos sobre o tipo de interação que se estabelece entre jogo e jogador e entre os usuários;

(v) conteúdo abordado - investigamos se os jogos contemplam atividades de leitura, produção de texto, tarefas que envolvam vocabulário, gramática, audição ou pronúncia, conteúdos que, geralmente, compõem o currículo de um processo de ensino-aprendizagem de LE;

(vi) interface - discutimos o aspecto gráfico-estrutural do jogo, o prazer despertado ou não pela interface e se ela é de fácil entendimento e manuseio, contemplando, assim, nossas experiências como jogadores.

No processo de seleção dos jogos, adotamos as seguintes etapas: pesquisa na plataforma Google Play, busca pelas palavras-chave "jogos" e "aprendizagem de línguas" e definição de critérios de seleção. Inicialmente, escolhemos o primeiro jogo da lista de pesquisa, no caso, o Lingualeo. A seguir, selecionamos aleatoriamente um jogo que abordasse a gramática e outro que se concentrasse na pronúncia, considerando nossa intenção de 
contemplar dois dos aspectos que geralmente fazem parte do currículo do processo de ensino-aprendizagem de LE.

\section{Análise dos jogos}

\subsection{Lingualeo}

De acordo com os resultados da pesquisa na Google Play, o aplicativo/ jogo mais utilizado é o Lingualeo, que apresenta, inclusive, o selo Top Developer. ${ }^{6}$ Segundo a descrição da app store, Lingualeo "é um aplicativo interativo e gamificado para o aprendizado e prática do inglês" e possui, atualmente, mais de 10.500.000 usuários. Está disponível em versões para computador e dispositivos móveis como tablets e smartphones, além de ser recomendado para crianças e adultos com qualquer nível linguístico. Ademais, alguns materiais são acessíveis apenas para usuários que desejam pagar para obter todos os recursos do aplicativo. A maioria desses recursos, porém, é gratuita.

Lingualeo possui um avatar em forma de leão, chamado Leo, responsável por guiar os usuários pela "selva do inglês". Para acessar o aplicativo, é necessário criar uma conta de usuário ou entrar com contas do Facebook ou Google+. Inicialmente, o usuário responde a uma série de perguntas relacionadas a seu perfil (idade, tempo disponível para estudo etc.), ao nível de habilidades linguísticas e às áreas de interesse pessoal (entretenimento, estilo de vida, tipo de tecnologia utilizada, grau de escolaridade etc.). Em seguida, é proposto um teste de nivelamento para definir o nível de conhecimento em gramática e vocabulário do usuário. Depois, é necessário selecionar uma meta de aprendizagem, que varia entre elevar seu nível de proficiência no idioma, estudar para exames de proficiência ou aperfeiçoar o inglês para fins profissionais. Desse modo, o aplicativo pode oferecer inúmeros materiais de estudo, de acordo com o perfil pessoal e os objetivos de cada usuário.

$\mathrm{Na}$ Figura 1, apresentamos as interações iniciais entre aplicativo e jogador:

\footnotetext{
${ }^{6} \mathrm{O}$ selo Top Developer é um modo de reconhecer desenvolvedores respeitados por seu compromisso com o lançamento de aplicativos inovadores e de alta qualidade para o sistema Android. Segundo a Google Play, o selo significa um nível adicional de confiança e segurança que os usuários têm em produtos de determinado desenvolvedor. Disponível em: <http://bit.ly/1FHn1tH>. Acesso em: 12 abr. 2016.
} 
FIGURA 1 - Interfaces de interações iniciais entre o aplicativo e o usuário

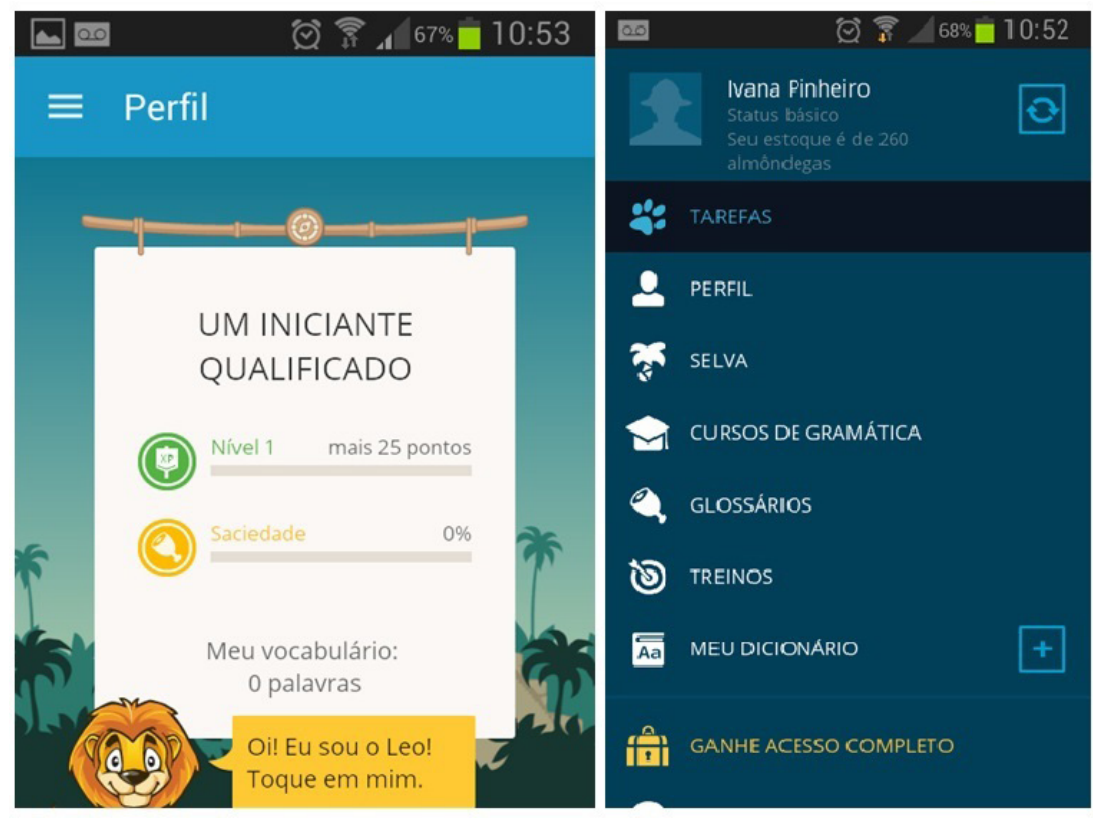

Fonte: Aplicativo Lingualeo. ${ }^{7}$

Como demonstra a Figura 1, a interface do aplicativo é bem elaborada e bastante amigável ${ }^{8}$, além de simples de ser manuseada. Para praticar o idioma, o usuário deve navegar pela "selva" onde encontrará uma vasta gama de materiais de compreensão auditiva (vídeos) e de leitura, prática de vocabulário por meio de flashcards traduzidos, cursos de gramática e glossários. No acervo do jogo, observamos uma diversidade de temas, tais como palestras sobre artes, educação e economia, além de poemas, piadas, animações e inglês para crianças, conteúdos que podem ser selecionados de acordo com os interesses de cada jogador. Após a realização de cada tarefa de estudo, o usuário acumula pontos de experiência e almôndegas virtuais para alimentar o Leo, que deve ser sustentado diariamente para manter seu nível de saciedade em 100\%.

\footnotetext{
${ }^{7}$ Disponível em: < http://bit.ly/1gP6bNa>. Acesso em: 12 abr. 2016.

${ }^{8}$ Segundo Salimen e Ramos (2011, p. 2), para que uma interface seja considerada amigável "ela deve seguir alguns parâmetros: ser de fácil utilização, possuir uma baixa taxa de erros, ser atrativa ao usuário, além de propiciar uma fácil memorização".
} 
O treino de vocabulário é apresentado por meio de uma série de flashcards com palavras isoladas em inglês, acompanhadas de uma imagem correspondente, tradução, áudio e escrita fonética. Após associar a imagem à palavra e à tradução, o usuário realiza alguns exercícios de memorização, como escrever a palavra referente à imagem a partir de letras embaralhadas, escolher a tradução apropriada em testes de múltipla escolha e ouvir a palavra e digitá-la.

Nas tarefas de leitura e compreensão auditiva, feitas por meio de vídeos com legendas em inglês, é possível, com um clique, acessar a tradução de todas as palavras que aparecem no texto e no vídeo, bem como adicionar palavras selecionadas ao dicionário pessoal do usuário, para treiná-las posteriormente.

Nos cursos de gramática, os tópicos são apresentados na língua nativa do usuário, com exemplos de frases em inglês. Após a explicação escrita do tópico gramatical, são feitas algumas perguntas de múltipla escolha (ainda em língua nativa) para avaliar o entendimento sobre o que foi explicado.

Analisando os tipos de tarefa promovidos pelo Lingualeo, observamos a predominância da abordagem behaviorista, marcada pela presença de exercícios de associação entre imagens-palavras e palavras-traduções. $\mathrm{O}$ estímulo positivo está em ganhar pontos de experiência a cada resposta correta e tarefa cumprida, assim como o estímulo negativo também está presente quando o usuário recebe feedback sobre determinado aspecto da língua que ainda não domina e que, por isso, deve ser treinado novamente.

De acordo com Filsecker e Bündgens-Kosten (2012, p. 52), a pedagogia implícita nas práticas behavioristas indica que é necessário "apresentar a informação para os aprendentes, criar oportunidades para a prática e, ao mesmo tempo, promover feedback que irá fortalecer as associações com o material". ${ }^{9}$ Nesse contexto, notamos a importância do feedback imediato e das frases de encorajamento do aplicativo, como "Ótima resposta! Continue assim”. Além disso, o avatar Leo atua continuamente com o intuito de manter uma atmosfera positiva durante a prática da língua. $\mathrm{Na}$ figura a seguir listamos exemplos das atividades comentadas:

\footnotetext{
9 "'To present information to the learners, make opportunities for practice, while giving learners specific feedback that will strenghten the associations of the material" (tradução nossa).
} 
FIGURA 2 - Exemplos de tarefas de vocabulário e compreensão auditiva
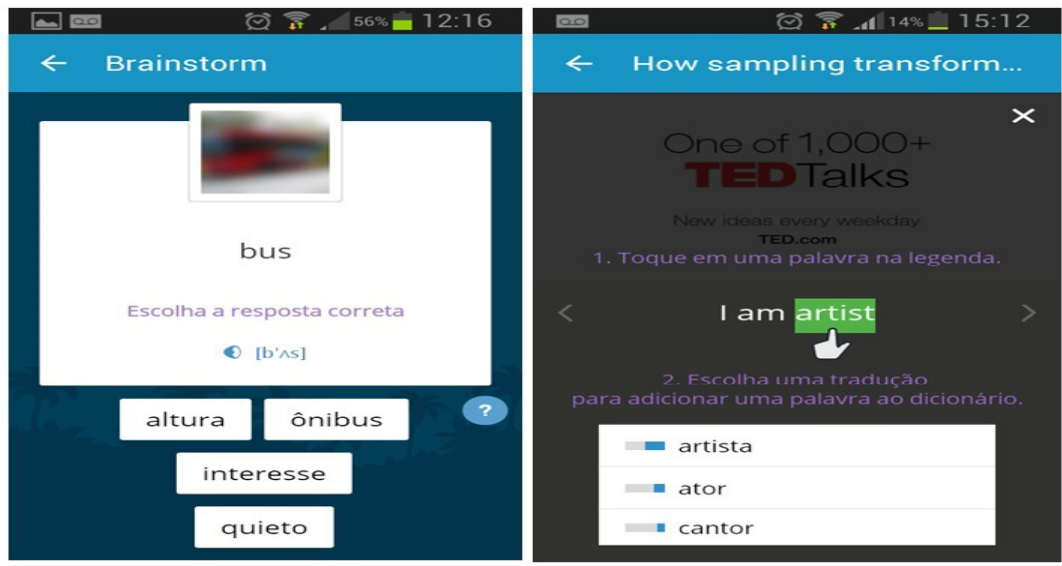

Fonte: Aplicativo Lingualeo.

Apesar da predominância de aspectos behavioristas, também observamos uma tentativa de promover disputa entre usuários. Alguns jogos de vocabulário permitem ao jogador comparar sua pontuação com a de outros usuários, a fim de estimular a competição atrelada à prática da língua. Compreendemos que tal tentativa é insuficiente para promover a construção do conhecimento de maneira colaborativa, o que poderia ocorrer, por exemplo, por meio da interação entre usuários, ainda inexistente (Figura 3).

FIGURA 3 - Interfaces de promoção de interação com demais usuários

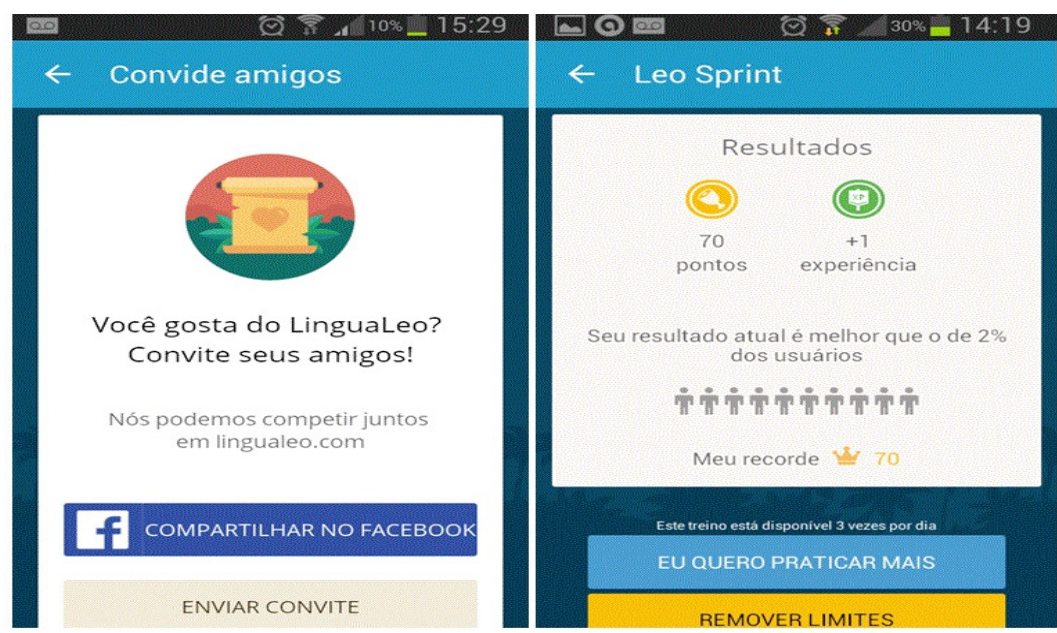

Fonte: Aplicativo Lingualeo. 
De modo geral, o aplicativo/jogo Lingualeo pode ser considerado inovador por disponibilizar uma grande quantidade de materiais diversos para a aprendizagem de inglês. Ao praticar o idioma, lendo um texto ou ouvindo uma música, os usuários têm a chance de contextualizar e assimilar o vocabulário apresentado. No entanto, o aplicativo carece de práticas que desenvolvam as habilidades de produção linguística oral e escrita, as quais, até o momento, se limitam à repetição de palavras após reprodução do áudio. Ademais, não há recursos de análise de voz nem de escrita das palavras aprendidas, isoladamente, nas atividades de vocabulário. Conclui-se, assim, que não há objetivos autênticos de comunicação propostos no aplicativo, ou seja, os usuários não têm a chance de utilizar o conteúdo aprendido em situações reais de comunicação.

\subsection{English Grammar All Levels}

O jogo English Grammar All Levels foi exclusivamente criado para a prática da gramática, apresentando questões de diversos níveis de proficiência, como indicado em sua denominação, abrangendo do nível elementar ao avançado. Em sua descrição na Google Play, os desenvolvedores mencionam que incluíram no aplicativo conteúdos sobre todos os tempos verbais, artigos, discurso direto e indireto, voz passiva, verbos compostos, comparação entre adjetivos, preposições, pronomes, colocações e muitos outros aspectos gramaticais necessários a uma imersão na língua inglesa. A Figura 4 apresenta a tela inicial do aplicativo: 
FIGURA 4 - Tela inicial do aplicativo English Grammar All Levels

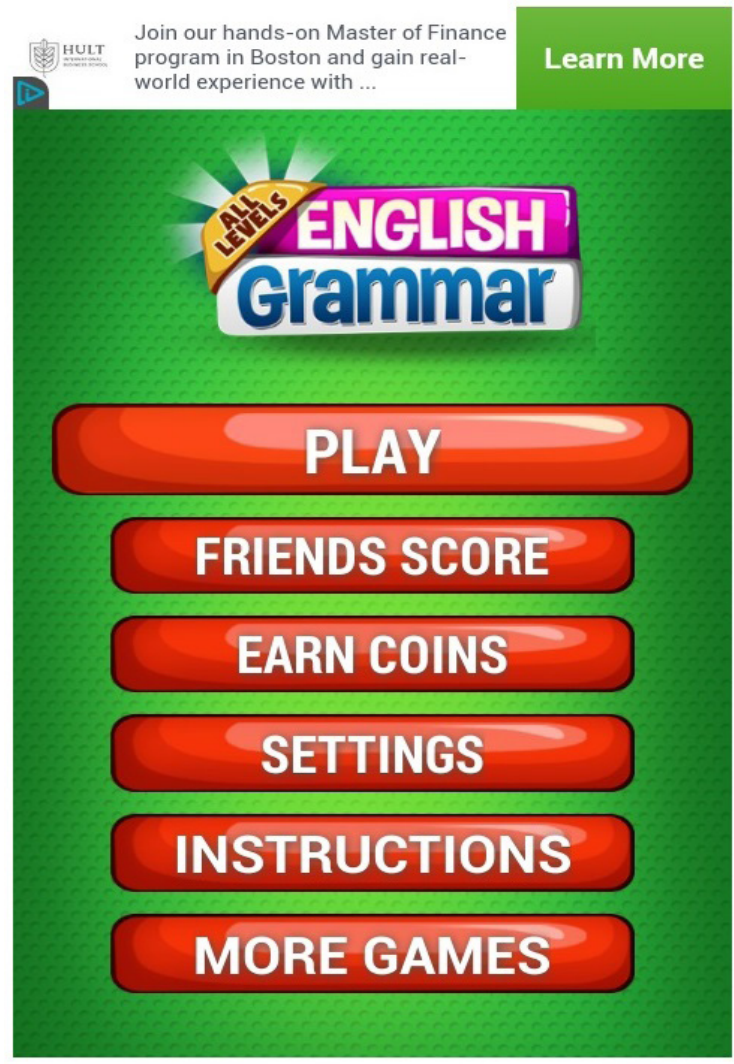

Fonte: Aplicativo English Grammar All Levels. ${ }^{10}$

Para acessar o English Grammar All Levels pode-se entrar com uma conta do Facebook ou como convidado. A dinâmica do jogo consiste em responder a perguntas diretas ou preencher lacunas em questões objetivas de múltipla escolha relativas ao uso da gramática. De acordo com as instruções fornecidas pelo jogo, cada questão possui quatro opções de resposta, sendo que apenas uma está correta. Cada questão deve ser respondida em até vinte segundos, e a cada resposta correta o usuário acumula moedas e pontos. No entanto, respostas incorretas não geram recompensa e não são consideradas. Ademais, para cada questão há três possibilidades de ajuda (remover duas opções incorretas da múltipla escolha, mudar a pergunta e

${ }^{10}$ Disponível em: <http://bit.ly/2tXJ98P>. Acesso em: 12 abr. 2016. 
ver as respostas dadas por outros usuários), que custam uma determinada quantidade de moedas. Essas ajudas ocorrem no âmbito do jogo, e não no do aprendizado, pois, ao ver as respostas de outros jogadores ou mudar a pergunta, o aluno não estará aprendendo, mas respondendo com base no que outros escolheram ou se esquivando de responder e, consequentemente, de aprender. A Figura 5 apresenta a dinâmica do jogo:

FIGURA 5 - Dinâmica do jogo English Grammar All Levels

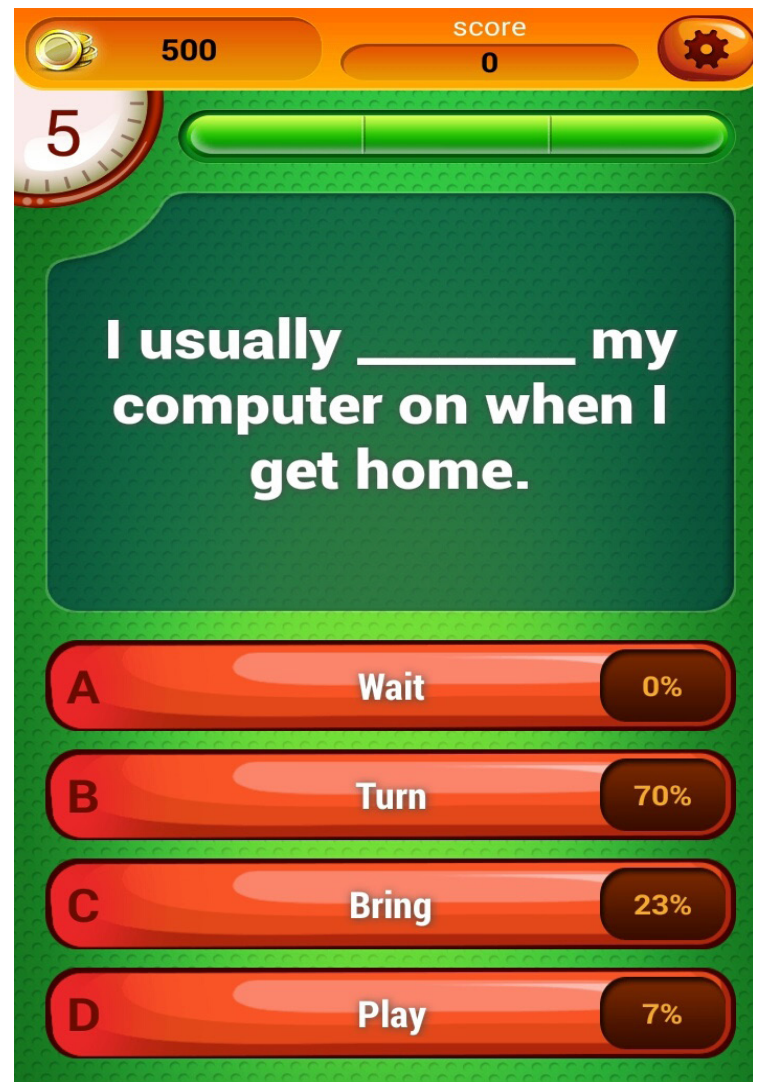

Fonte: Aplicativo English Grammar All Levels.

O jogo apresenta o cronômetro no canto superior esquerdo, a pergunta ao centro, seguida das alternativas e, no final da tela, as opções de ajuda. Na Figura 5, a opção que permite ver a porcentagem de respostas dadas por outros usuários está ativada. 
O jogo não disponibiliza recurso para que o usuário trace seu perfil nem faz perguntas relacionadas à aprendizagem ou ao nível de conhecimento linguístico. Dessa maneira, não pode ser personalizado, o que pode desmotivar o usuário, causar desinteresse ou, ainda, contribuir pouco para uma aprendizagem efetiva da língua estrangeira. Também contribui nesse sentido a abordagem behaviorista de ensino da língua, baseada na estrutura frasal e na possibilidade de se obter a resposta correta por meio das respostas já dadas. Além da lógica de recompensa, o jogo oferece, como estímulo negativo, a perda de moedas e a finalização do jogo sem apontar as respostas corretas. Esse processo pode ser mais bem observado na Figura 6:

FIGURA 6 - Processo de estímulo/recompensa no jogo English Grammar All Levels
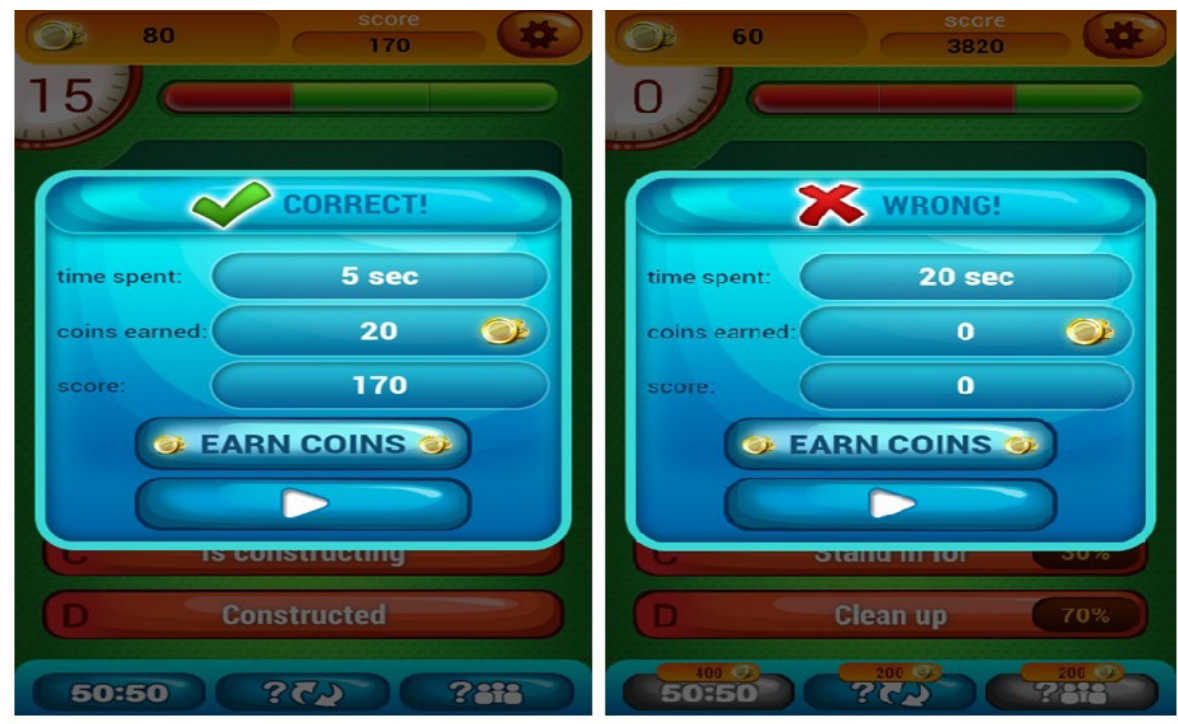

Fonte: Aplicativo English Grammar All Levels.

Cabe destacar também que a interação se limita à relação jogojogador, visto que o contato entre jogadores (amigos do Facebook) ocorre somente para comparar a pontuação. Esse aspecto, mais uma vez, remete ao behaviorismo, visto que podemos compreender os resultados da comparação como um reforço positivo ou negativo dado às respostas dos usuários.

Finalmente, a interface do jogo, apesar de simples e amigável, apresenta o inconveniente de dividir espaço com propagandas recorrentes, postadas no canto superior da tela. 


\subsection{Learning 2 Talk}

O Learning 2 Talk é um jogo gratuito para smartphone, compatível com todos os dispositivos. Segundo a descrição no Google Play, o aplicativo se propõe a ensinar a falar inglês de forma divertida, escutando as palavras pronunciadas pelo usuário e avaliando sua performance. Os desenvolvedores também descrevem o jogo como adequado tanto para crianças quanto para adultos. Na Figura 7, apresentamos a tela inicial do aplicativo:

FIGURA 7 - Tela inicial do aplicativo Learning 2 Talk

Choose a set

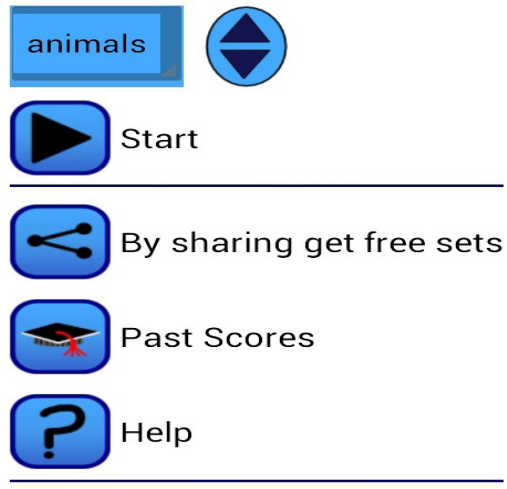

Fonte: Aplicativo Learning 2 Talk. ${ }^{11}$

A dinâmica do jogo se processa por meio da escolha de um tema central, como animals, actions, body, fellings. Após selecionar o tema, o jogo apresenta uma imagem que corresponde a uma palavra e, a partir daí, o usuário seleciona a opção de microfone e pronuncia a palavra, enquanto o aplicativo analisa o que foi dito. A pronúncia é considerada correta quando o som é reconhecido. No entanto, algumas vezes, mesmo quando as palavras são pronunciadas corretamente, o aplicativo pode apresentar alguns problemas de reconhecimento do som. A Figura 8 reproduz a dinâmica do jogo:

11 Disponível em: <http://bit.ly/2tXydYU>. Acesso em: 12 abr. 2016. 
FIGURA 8 - Análise das palavras pronunciadas no tema

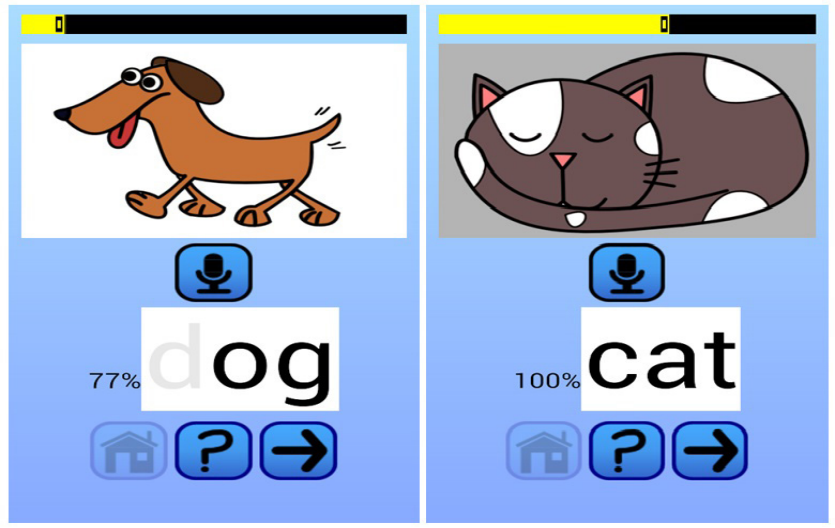

Fonte: Aplicativo Learning 2 Talk.

Ao final de cada conjunto de palavras, um conceito (A, B, C) é atribuído à performance do usuário. $\mathrm{O}$ desempenho pode ser compartilhado pelas principais redes sociais. Percebemos, então, que não há interação entre diferentes usuários, e sim a repetição de palavras sem contextualização. Portanto, nesse jogo também predomina a abordagem behaviorista, cuja concepção de aprendizagem se define pela técnica de estímulo-resposta, sendo o estímulo a pontuação em formato de conceitos, e a resposta, a análise mecânica da pronúncia, sem imersão em contextos situacionais de comunicação que favoreçam a fluência no idioma.

Com base na análise de cada um dos jogos, podemos compará-los, como demonstra o Quadro 2: 
QUADRO 2 - Comparativo entre os jogos

\begin{tabular}{|c|c|c|c|}
\hline & Lingualeo & $\begin{array}{l}\text { English } \\
\text { Grammar All } \\
\text { Levels }\end{array}$ & Learning 2 Talk \\
\hline $\begin{array}{c}\text { Teoria de } \\
\text { aprendizagem }\end{array}$ & Behaviorismo. & Behaviorismo. & Behaviorismo. \\
\hline $\begin{array}{c}\text { Nível de } \\
\text { contextualização }\end{array}$ & $\begin{array}{l}\text { As atividades de leitura e } \\
\text { de compreensão auditiva } \\
\text { propostas estão inseridas em } \\
\text { diversos temas, tais como } \\
\text { letras de música, piadas, } \\
\text { vídeos sobre assuntos } \\
\text { diversos etc., porém as } \\
\text { tarefas direcionadas ao } \\
\text { treino de vocabulário } \\
\text { tratam das palavras } \\
\text { isoladamente, sem contexto } \\
\text { comunicacional. }\end{array}$ & Ausente. & Ausente. \\
\hline $\begin{array}{c}\text { Nível de } \\
\text { personalização }\end{array}$ & $\begin{array}{c}\text { A aprendizagem é } \\
\text { direcionada às necessidades } \\
\text { e aos objetivos mencionados } \\
\text { por cada usuário. }\end{array}$ & Ausente. & $\begin{array}{l}\text { O usuário somente } \\
\text { escolhe a classe de } \\
\text { palavras com a qual } \\
\text { quer trabalhar. }\end{array}$ \\
\hline Tipo de interação & $\begin{array}{l}\text { Não há interação aparente } \\
\text { entre os usuários; é possível } \\
\text { apenas indicar o app para } \\
\text { amigos com o intuito } \\
\text { de competir em nível de } \\
\text { pontuação. }\end{array}$ & $\begin{array}{l}\text { Não há interação } \\
\text { entre os usuários; } \\
\text { é possível apenas } \\
\text { ver a pontuação } \\
\text { de amigos do } \\
\text { Facebook. }\end{array}$ & $\begin{array}{l}\text { Não há interação } \\
\text { entre os usuários; } \\
\text { é possível apenas } \\
\text { compartilhar a } \\
\text { pontuação no } \\
\text { Facebook. }\end{array}$ \\
\hline $\begin{array}{l}\text { Conteúdo } \\
\text { abordado }\end{array}$ & $\begin{array}{l}\text { Vocabulário é treinado por } \\
\text { meio de flashcards e atividades } \\
\text { de leitura e compreensão } \\
\text { auditiva. Separadamente, } \\
\text { trabalham-se também } \\
\text { aspectos de gramática. }\end{array}$ & $\begin{array}{l}\text { Gramática } \\
\text { (atividades de } \\
\text { preenchimento } \\
\text { de lacunas). }\end{array}$ & $\begin{array}{l}\text { Pronúncia de } \\
\text { palavras isoladas. }\end{array}$ \\
\hline Interface & Elaborada e amigável. & $\begin{array}{l}\text { Simples e } \\
\text { amigável, } \\
\text { com algumas } \\
\text { propagandas. }\end{array}$ & $\begin{array}{l}\text { Extremamente } \\
\text { simples, porém } \\
\text { amigável. }\end{array}$ \\
\hline
\end{tabular}

Baseados em Cornillie, Thorne e Desmet (2012), analisamos os jogos em relação a tipos de atividade possíveis, ações necessárias por parte do jogador e oportunidades de aprendizagem, conforme apresentado no Quadro 3: 
QUADRO 3 - Comparativo entre os aspectos estruturais dos jogos

\begin{tabular}{|c|c|c|c|}
\hline & Lingualeo & $\begin{array}{l}\text { English Grammar } \\
\text { All Levels }\end{array}$ & Learning 2 Talk \\
\hline Diversão & Sim. & Sim. & Sim. \\
\hline Regras & Sim. & Sim. & Sim. \\
\hline Metas & $\begin{array}{c}\text { A meta principal é } \\
\text { pessoal e definida por } \\
\text { cada usuário. }\end{array}$ & $\begin{array}{l}\text { Acertar todas as } \\
\text { questões em vinte } \\
\text { segundos e superar } \\
\text { o score dos amigos. }\end{array}$ & $\begin{array}{l}\text { Acertar a pronúncia } \\
\text { das palavras } \\
\text { representadas nas } \\
\text { imagens. }\end{array}$ \\
\hline Interação & $\begin{array}{l}\text { Somente comparação de } \\
\text { pontuação e resultados. }\end{array}$ & Não há interação. & Não há interação. \\
\hline $\begin{array}{l}\text { Resultados e } \\
\text { feedback }\end{array}$ & $\begin{array}{l}\text { A cada tarefa realizada } \\
\text { há feedback positivo } \\
\text { ou negativo, com a } \\
\text { obtenção de pontos } \\
\text { de experiência. Porém, } \\
\text { todo feedback apresenta } \\
\text { frases de encorajamento. }\end{array}$ & $\begin{array}{l}\text { Feedback positivo } \\
\text { somente em caso } \\
\text { de acerto. No caso } \\
\text { de extrapolação } \\
\text { do limite de } \\
\text { tempo, a questão é } \\
\text { considerada errada, } \\
\text { mas a resposta } \\
\text { correta não é } \\
\text { fornecida. }\end{array}$ & $\begin{array}{l}\text { Feedback positivo em } \\
\text { caso de acerto. Quando } \\
\text { a palavra é pronunciada } \\
\text { de modo errado ou } \\
\text { não é identificada } \\
\text { completamente, apenas } \\
\text { o som identificado } \\
\text { aparece para o usuário, } \\
\text { indicando os fonemas } \\
\text { que precisam ser } \\
\text { pronunciados mais } \\
\text { claramente. }\end{array}$ \\
\hline $\begin{array}{l}\text { Solução de } \\
\text { problemas/ } \\
\text { competição/ } \\
\text { desafio }\end{array}$ & $\begin{array}{l}\text { Há possibilidade de } \\
\text { comparar resultados, } \\
\text { estimulando, assim, } \\
\text { a competição entre } \\
\text { usuários amigos. }\end{array}$ & $\begin{array}{c}\text { Há possibilidade } \\
\text { de eliminar } \\
\text { duas respostas } \\
\text { erradas, consultar } \\
\text { a estatística de } \\
\text { respostas mais } \\
\text { dadas ou saltar a } \\
\text { questão. O desafio } \\
\text { é superar o score dos } \\
\text { amigos. }\end{array}$ & $\begin{array}{l}\text { Há possibilidade de } \\
\text { consultar a palavra } \\
\text { escrita, apertando o } \\
\text { botão display english, ou } \\
\text { de escutar a palavra, } \\
\text { clicando no ícone do } \\
\text { autofalante. }\end{array}$ \\
\hline $\begin{array}{l}\text { Representação/ } \\
\text { contexto }\end{array}$ & $\begin{array}{c}\text { O jogo é } \\
\text { contextualizado } \\
\text { pela criação de um } \\
\text { ambiente de "selva", } \\
\text { onde o usuário recebe } \\
\text { ajuda de um leão para } \\
\text { navegar pelos materiais } \\
\text { oferecidos. }\end{array}$ & $\begin{array}{l}\text { A contextualização } \\
\text { ocorre somente } \\
\text { entre o termo e a } \\
\text { oração. }\end{array}$ & $\begin{array}{c}\text { Apresenta imagens/ } \\
\text { palavras agrupadas por } \\
\text { tópicos. }\end{array}$ \\
\hline
\end{tabular}


É fundamental, ainda, analisar comparativamente os conteúdos abordados pelos jogos, as ações requeridas dos jogadores e as contribuições para a aprendizagem, conforme o quadro a seguir:

QUADRO 4 - Comparativo entre as habilidades, competências e conteúdos trabalhados pelos jogos

\begin{tabular}{|c|c|c|c|}
\hline & Lingualeo & $\begin{array}{c}\text { English Grammar All } \\
\text { Levels }\end{array}$ & Learning 2 Talk \\
\hline $\begin{array}{l}\text { Atividades } \\
\text { possíveis }\end{array}$ & $\begin{array}{l}\text { Leitura de textos } \\
\text { diversos, vídeos, questões } \\
\text { de memorização de } \\
\text { vocabulário e cursos de } \\
\text { gramática. }\end{array}$ & $\begin{array}{l}\text { Questões de múltipla } \\
\text { escolha. }\end{array}$ & $\begin{array}{l}\text { Gravação de } \\
\text { áudio (fala/ } \\
\text { pronúncia). }\end{array}$ \\
\hline $\begin{array}{l}\text { Ações do } \\
\text { jogador }\end{array}$ & $\begin{array}{c}\text { A partir da leitura e } \\
\text { compreensão auditiva, } \\
\text { selecionar novas palavras } \\
\text { para treino de vocabulário. }\end{array}$ & $\begin{array}{l}\text { Preencher lacunas, } \\
\text { escolhendo uma das } \\
\text { opções oferecidas. }\end{array}$ & $\begin{array}{l}\text { Associar a } \\
\text { imagem fornecida } \\
\text { a uma palavra e } \\
\text { pronunciar. }\end{array}$ \\
\hline $\begin{array}{l}\text { Oportunidades } \\
\text { de } \\
\text { aprendizagem }\end{array}$ & $\begin{array}{l}\text { Pelo treino sistematizado } \\
\text { de vocabulário e pelo } \\
\text { contato com materiais } \\
\text { autênticos da língua-alvo. }\end{array}$ & $\begin{array}{c}\text { Apesar de } \\
\text { características lúdicas, } \\
\text { como score, premiação e } \\
\text { punição, as estratégias } \\
\text { têm função de testar } \\
\text { conhecimento. Assim, } \\
\text { o jogador pode } \\
\text { aprender ao acertar } \\
\text { acidentalmente e ao } \\
\text { consultar a ferramenta } \\
\text { de ajuda, que mostra } \\
\text { a porcentagem de } \\
\text { respostas de outros } \\
\text { jogadores. }\end{array}$ & $\begin{array}{l}\text { Pelo feedback da } \\
\text { pronúncia. }\end{array}$ \\
\hline
\end{tabular}

Diante do exposto nos Quadros 2, 3 e 4, percebemos que os jogos, embora contribuam para o ensino de determinados conhecimentos de inglês, poderiam promover maior interação entre o jogador, as ferramentas e a língua em fase de aprendizagem, inserindo o aprendiz em contextos situacionais de autêntica imersão no idioma, não se baseando somente na perspectiva behaviorista, marcada por estímulos-respostas destituídos de contextualização real. Por meio de atividades diferenciadas, que se preocupem não apenas com normas e estruturas da língua, mas também com a exploração dos gêneros discursivos - pelos quais grande parte da comunicação acontece -, acreditamos que as expectativas em relação 
à mecânica e interface dos jogos educacionais devam se aproximar da sofisticação dos games de entretenimento, que há anos seduzem os jovens a vencer desafios por longos períodos.

\section{Considerações finais}

Enquanto a escola discute a inserção das tecnologias digitais como ferramentas pedagógicas, questionando se o uso de celulares pelos jovens faz com que fiquem dispersos nas aulas, muitas vezes escondidos em um canto da sala, os meios informais de ensino e aprendizagem vão se tornando cada vez mais frequentes na internet. Hoje é comum ouvirmos falar de pessoas que aprenderam uma segunda ou terceira língua por meio de aplicativos de celular. As relações de aprendizagem verticais estão convivendo lado a lado com as horizontais, ou seja, inúmeros ambientes têm se configurado para promover o aprendizado de forma autônoma.

Essa realidade impõe desafios para a escola, quase que as obrigando a não mais se privar da voracidade das tecnologias digitais e de seus impactos nas salas de aula. O letramento digital, em uma sociedade cada vez mais tecnológica, torna-se tópico indispensável nos currículos escolares. Em decorrência dessa necessidade, inúmeras propostas têm procurado promover novos letramentos por meio de recursos tecnológicos, de modo que se torna importante discutir essas iniciativas e questionar até que ponto, de fato, contribuem para letrar digitalmente os alunos.

Nesse sentido, analisamos três sugestões de jogos digitais (mobile games) para desenvolver atividades de ensino de LE, no caso, o inglês, em sala de aula: Lingualeo, English Grammar All Levels e Learning 2 Talk. Se, por um lado, essas iniciativas representam o ensino de língua por meio de jogos digitais, utilizando as tecnologias no treino de tópicos linguísticos, sobretudo nas atividades de vocabulário, carecem, por outro, da promoção de atividades contextualizadas.

Mesmo que esses instrumentos necessitem de uma análise criteriosa de qualidade no que tange aos aspectos didático-pedagógicos, constituem ferramentas que exploram os conteúdos de forma lúdica. Contudo, isso não é suficiente para que se tornem excelentes ferramentas de ensinoaprendizagem, uma vez que os usuários acabam, quase que exclusivamente, seguindo comandos, sendo direcionados a respostas "certas" ou "erradas", sem considerar um contexto real de aplicação da língua. 
É importante ressaltar que, embora Lingualeo, English Grammar All Levels e Learning 2 Talk apresentem uma perspectiva behaviorista em suas propostas, é o professor o responsável por orientar a exploração das atividades de forma interativa.

Os jogos analisados exigem conhecimentos básicos de computação, do que depende o desenvolvimento das tarefas, principalmente se considerarmos o uso pelo professor em sala de aula. No entanto, é preciso ampliar as pesquisas na área de ensino de línguas e tecnologias, de modo que as propostas se configurem em um cenário mais colaborativo, autônomo e multifacetado e, de fato, possam imergir os aprendizes em processos comunicativos mais autênticos.

Os jogos podem desenvolver várias capacidades que auxiliam o aprendizado, como concentração, raciocínio rápido, ação e interação, principalmente sob uma perspectiva de criação atrativa, por serem divertidos e desafiadores. Nesse sentido, os três objetos analisados, muito embora sejam repetitivos e focalizem conhecimentos estruturais, sem inserção em práticas sociais da língua em aprendizagem, podem ser aproveitados em sala de aula, dado seu caráter lúdico, até para segmentos iniciantes da língua inglesa.

Ao término de toda pesquisa, sempre surge o desejo de investigar um pouco mais. Acreditamos que desenvolver esse tipo de estudo seja uma boa maneira de mostrar um protocolo a outros pesquisadores para novas investigações ou mesmo para análise de outros jogos. As pessoas, durante toda sua trajetória de vida, estão sempre em busca de descobertas e aprendizados novos através do contato com outras pessoas, com o meio em que se inserem, e, em grande parte do tempo, com o espaço cibernético. Diante disso, potencializar a aprendizagem com o uso de recursos tecnológicos passa a ser de extrema importância, desde que essa potencialização seja feita adequadamente, de forma bem planejada em sala de aula, para representar novas possibilidades de letramento e contribuir para a participação dos alunos em uma sociedade fortemente influenciada pelas tecnologias digitais.

\section{Referências}

ARMELIATO, E. Jogos computacionais na educação: uma aplicação ao ensino de música. Universidade Estadual de Campinas. 2011.155 p.. Dissertação (Mestrado) Universidade Estadual de Campinas, Faculdade de Engenharia Elétrica e de Computação. Campinas,SP, 2011. Disponível em: <http://www.bibliotecadigital. unicamp.br/document/?code $=000866955>$. Acesso em: 1 abr. 2017. 
CORNILLIE, F.; THORNE, S. L.; DESMET, Piet. ReCALL special issue: digital games for language learning: challenges and opportunities. ReCALL, Portland, v. 24, n. 3, p. 243-256, 2012. DOI: https://doi.org/10.1017/S0958344012000134. COSCARELLI, C. V. Linkando as ideias dos textos. In: ARAÚJO, J. C. A.; DIEB, M. (Org.). Letramentos na web: gêneros, interação e ensino. Fortaleza: UFC, p. 13-20, 2009.

DETERDING, S. et. al. From game design elements to gamefulness: defining "gamification". MindTrek'11. INTERNATIONAL ACADEMIC MINDTREK CONFERENCE: ENVISIONING FUTURE MEDIA ENVIRONMENTS, 15, 2011. New York, Proceedings... 2011. p. 9-15. DOI: https://doi. org/10.1145/2181037.2181040.

DOMÍNGUEZ, A. et al. Gamifying learning experiences: practical implications and outcomes. Computers \& Education, Madrid, v. 63, p. 380-392, 2013. DOI: https://doi.org/10.1016/j.compedu.2012.12.020.

FADEL, L. M.; ULBRICHT, V. R. Educação gamificada: valorizando os aspectos sociais. In: FADEL, L. et. al. (Org.). Gamificação na educação. São Paulo: Pimenta Cultural, 2014. p. 6-10.

FARDO, M. L. A gamificação como estratégia pedagógica: estudo de elementos dos games aplicados em processos de ensino e aprendizagem. 2013. Dissertação (Mestrado em Educação) - Universidade de Caxias do Sul, Caxias do Sul, 2013.

FILSECKER, M.; BÜNDGENS-KOSTEN, J. Behaviorism, constructivism, and communities of practice: how pedagogic theories help us understand game-based language learning. In: REINDERS, H. (Ed.). Digital games in language learning and teaching: new language learning and teaching environments. New York: Palgrave and Macmillan, 2012. p. 50-69. DOI: https://doi.org/10.1057/9781137005267_4.

FORTIM, I. Psicologia e games: uma experiência de ensino realizada no curso superior de tecnologia em jogos digitais da PUC-SP. In: SIMPÓSIO BRASILEIRO DE JOGOS E ENTRETENIMENTO DIGITAL, 7, 2008, Belo Horizonte. Belo Horizonte: PUC-Minas, UFMG, 2008. p. 139-141.

FURIÓ, D. et al. The effects of the size and weight of a mobile device on an educational game. Journal Computers \& Education, Virginia, v. 64, p. 24-41, 2013. DOI: https://doi.org/10.1016/j.compedu.2012.12.015.

HEALEY, D.; JOHNSON, N. TESOL CALL interest section software list. Alexandria, VA: TESOL, 1995.

KAPP, K. The Gamification of learning and instruction: game-based methods and strategies for training and education. Hoboken: Pfeiffer, 2012. DOI: https://doi. org/10.1016/j.learninstruc.2011.12.002. 
LEE, H.; DOH, Y. Y. A. Study on the relationship between educational achievement and emotional engagement in a gameful interface for video lecture systems. In: INTERNATIONAL SYMPOSIUM ON UBIQUITOUS VIRTUAL REALITY, 7, 2012. Daejon, Proceedings... 2012. p. 34-37. DOI: https://doi.org/10.1109/ ISUVR.2012.21.

LEVY, M. Computer-assisted language learning: context and conceptualization. Oxford: Clarendon, 1997. (OxfordLinguistics). DOI: https://doi.org/10.1080/0958822970100103. MCGONIGAL, J. Reality is broken: why games make us better and how they can change the world. Nova York: Penguin, 2011.

MCGONIGAL, J. Games. 2014. Disponível em: <http://janemcgonigal.com/ play-me/>. Acesso em: 6 abr. 2016.

OKAN, Z. Edutainment: Is Learning at Risk? British Journal of Educational Technology, v.34, p. 255-264, 2003. DOI: https://doi.org/10.1111/1467-8535.00325.

PELLING, N. The (short) prehistory of gamification. 9 ago. 2011. Disponível em: <https:// nanodome.wordpress.com/2011/08/09/the-short-prehistory-ofgamification/>. Acesso em: 8 maio 2016.

SALEN, K.; ZIMMERMAN, E. Regras do jogo: fundamentos do design de jogos. São Paulo: Blucher, 2012. v. 1.

SALIMEN, S. S.; RAMOS, C. R. Avaliação da usabilidade dos sítios das universidades federais do extremo sul do Brasil. Múltiplos Olhares em Ciência da Informação, Belo Horizonte, v. 1, n. 2, 2011.

TAYLOR, M. B.; PEREZ, L. M. Something to do on monday. La Jolla: Athelstan, 1989.

VIANNA, Y.et. al. Gamification, Inc: como reinventar empresas a partir de jogos. Rio de Janeiro: MJV, 2013.

WARSCHAUER, M. Computer assisted language learning: an introduction. In: FOTOS, S. (Ed.). Multimedia language teaching. Tokyo: Logos International, 1996. Disponível em: <http://bit.ly/1Ei6uP6>. Acesso em: 28 jul. 2017.

WARSCHAUER, M.; HEALEY, D. Computers and language learning: an overview. Language teaching, Cambridge, v. 31, n. 02, p. 57-71, 1998.

YOZO, R. Y. K. 100 jogospara grupos: uma abordagem psicodramática para empresas, escolas e clínicas. São Paulo: Ágora, 1996.

ZICHERMANN, G.; CUNNINGHAM, C. Gamification by design: implementing game mechanics in web and mobile apps. Sebastopol, CA: O'Reilly Media, 2011.

Data de submissão: 23/04/2017. Data de aprovação: 27/06/2017. 
